\title{
Wind energy in Taiwan and the standard of communication for wind turbines
}

\author{
Yun-Wei Lin ${ }^{\mathrm{a}}$, Yung-Hsiang Wu ${ }^{\mathrm{a}}$, Cheng-Chang Chen ${ }^{\mathrm{b}}$, Jian-Li Dong ${ }^{\mathrm{b}, \mathrm{a} *}$ \\ ${ }^{a}$ Electronics Testing Center, No.8, Ln. 29, Wenming Rd., Guishan Dist., Taoyuan City 333, Taiwan (R.O.C.) \\ ${ }^{b}$ Bureau of Standards, Metrology and Inspection, Ministry of Economic Affairs, No.157, Jiadong Rd., Xizhi Dist., New Taipei City \\ 221, Taiwan (R.O.C.)
}

\begin{abstract}
In this paper, we will introduce the development of wind energy in Taiwan and the policies or subsidies issued by government of Taiwan for development of offshore farm, which includes Formosa Wind Power (FWP), Fuhai Wind Farm (FWF) and Taiwan Power Company (TPC) offshore demonstration sites. Then, we will focus on the IEC 61400-25 which is the communication standard for control and monitoring of wind turbines. The information models and information exchange model are used to describe the services provided by the wind power plant. The mapping from the models to the communication profiles and the condition in Taiwan are then illustrated.
\end{abstract}

Keywords: Wind power plants, IEC 61400-25, wind turbine, communication protocol, information model

\section{Introduction}

With the growth of global economy, developed and developing countries consume more and more energy. The use of fossil fuels even increases the risk of climate change. In order to improve the problem of energy crises and climate change, lots of countries are active in developing renewable energy, such as wind power, solar energy, hydropower, geothermal energy.

Among various renewable energy, wind power is a well-developed technology to produce energy by wind. It can be divided into two categories, onshore and offshore. An offshore wind farm, such as the London Array, is even with a capacity of 630MW which, by yearly average, is sufficient to supply approximately more than 480,000 homes. In order to deal with such a large amount of capacity connecting to the main power system, the control and monitoring becomes more and more important in this system, especially the communication protocol. There are some standards have profiled the communication between power system and wind turbines, but it cannot be sure that the interoperability between these standards. In order to resolve the problems that the wind turbines from different vendors may not be able to communicate with each other, and the SCADA system may not interoperate with different wind turbines. The IEC 61400-25 series standards are promoted [1]-[6]. It increases the interoperability between wind turbines from different vendors.

\section{Wind Energy in Taiwan}

Taiwan is surrounded by the sea. The geographic environment and wind source is perfect to develop wind energy. Especially in the west coast of Taiwan and Penghu area, the winter northeast monsoon and the summer southwest monsoon is a great potential for developing wind power.

\footnotetext{
* Manuscript received June 25, 2015; revised August 17, 2015.

Corresponding author. Tel.: +886-3-328-0026; E-mail address: saxon@etc.org.tw.

doi: $10.12720 /$ sgce.4.4.328-335
} 


\subsection{Onshore wind energy}

In 1980, due to the crisis of energy, renewable energy became important. Industrial Technology Research Institute (ITRI) had been entrusted by the government of Taiwan to assess the potential of wind power for Taiwan and develop the technology of wind power in Taiwan. In the end of 1991, they complete the $4 \mathrm{~kW}, 40 \mathrm{~kW}$, and $150 \mathrm{~kW}$ wind power electricity generator.

In 2000, the government of Taiwan issued the "Wind Power Demonstration Incentive Program". The government provides subsidy for both equipment and developing processes. Due to these successful experiences in onshore wind power, more and more manufacturers are willing to invest in wind power in Taiwan.

\subsection{Offshore wind energy}

The advantage of the offshore wind power is that the wind is much stronger than the wind over the continent. Table 1 is the rank of average wind speed in 23 years which is evaluated by $4 \mathrm{C}$ Offshore. Taiwan has the great potential to develop offshore wind power [7]. But the development of offshore wind power needs lots of technologies, such as remote monitoring and control system and the offshore foundations. It made this expensive energy generating technology keep on hold in Taiwan.

However, after the Fukushima Nuclear Power Plant accidents, people are seeking new energy to substitute the nuclear power. The large scale deployment of offshore wind power becomes a solution to resolve the problem.

Table 1. Rank of average wind speed in 23 years (4Coffshore)

\begin{tabular}{|c|c|c|c|c|}
\hline Rank & Project & Sea & City & $\begin{array}{l}\text { Speed } \\
(\mathrm{m} / \mathrm{s})\end{array}$ \\
\hline 1 & $\begin{array}{l}\text { Fujian Pingtan Development Zone Changjiangao } \\
\text { 200MW offshore Wind Farm }\end{array}$ & South China Sea & China & 12.11 \\
\hline 1 & Putian Pinghai bay offshore project phase D-E & Taiwan Strait & China & 12.11 \\
\hline 1 & $\begin{array}{l}\text { Pingtan experimental zone } 300 \mathrm{MW} \text { offshore wind } \\
\text { power project }\end{array}$ & South China Sea & China & 12.11 \\
\hline 4 & Fujian Putian Shicheng Yugang Offshore Wind Farm & Taiwan Strait & China & 12.06 \\
\hline 5 & $\begin{array}{l}\text { Putian Pinghai bay offshore Wind Farm } \\
\text { demonstration project phase 2-250MW }\end{array}$ & Taiwan Strait & China & 12.04 \\
\hline 5 & $\begin{array}{l}\text { Longyuan Putian Nanri Island 400MW project - } \\
\text { Phase } 3 \text { 350MW Commercial }\end{array}$ & Taiwan Strait & China & 12.04 \\
\hline 5 & $\begin{array}{l}\text { Longyuan Putian Nanri Island 400MW project - } \\
\text { Phase 2-34MW Commercial }\end{array}$ & Taiwan Strait & China & 12.04 \\
\hline 5 & $\begin{array}{l}\text { Longyuan Putian Nanri Island 400MW project - } \\
\text { Phase 1- 16MW Commercial }\end{array}$ & Taiwan Strait & China & 12.04 \\
\hline 5 & $\begin{array}{l}\text { Putian Pinghai bay offshore demonstration project } \\
\text { phase A }\end{array}$ & Taiwan Strait & China & 12.04 \\
\hline 10 & Xidao - TGC & Taiwan Strait & Taiwan & 12.02 \\
\hline 10 & Zangfang - TGC & Taiwan Strait & Taiwan & 12.02 \\
\hline 10 & Changhua - North - Taipower & Taiwan Strait & Taiwan & 12.02 \\
\hline 13 & Changhua - South - Taipower & Taiwan Strait & Taiwan & 11.94 \\
\hline 13 & Changhua - Pilot - Taipower & Taiwan Strait & Taiwan & 11.94 \\
\hline 13 & Hanbao - TGC & Taiwan Strait & Taiwan & 11.94 \\
\hline 13 & Changhua Offshore Pilot Project (COPP) - TGC & Taiwan Strait & Taiwan & 11.94 \\
\hline 13 & Fuhai Offshore Windfarm - TGC & Taiwan Strait & Taiwan & 11.94 \\
\hline 13 & Fuhai Phase III - TGC & Taiwan Strait & Taiwan & 11.94 \\
\hline 19 & $\begin{array}{l}\text { NW1 Medium Term Option for Offshore Wind } \\
\text { Development }\end{array}$ & $\begin{array}{l}\text { Scottish Continental } \\
\text { Shelf }\end{array}$ & Scottish & 11.91 \\
\hline 20 & $\begin{array}{l}\text { NW2 Medium Term Option for Offshore Wind } \\
\text { Development }\end{array}$ & $\begin{array}{l}\text { Scottish Continental } \\
\text { Shelf }\end{array}$ & Scottish & 11.86 \\
\hline
\end{tabular}

On 3rd July, 2012, Taiwan government officially announced the "Offshore Demonstration Incentive Program" and provided subsidies for both equipment and developing processes for offshore wind power. Taiwan's Ministry of Economic Affairs (MOEA) had signed deals with Formosa Wind Power (FWP), 
Fuhai Wind Farm (FWF) and Taiwan Power Company to build three offshore demonstration sites on the west coast of Taiwan.

As shown in Table 2, the government of Taiwan had also set the "Thousand Wind Turbines Project". The goal is to build $600 \mathrm{MW}$ of offshore wind energy by 2020 and 3GW by 2030. By the end of 2030, there would be a thousand of offshore and onshore wind turbines in Taiwan. The Bureau of Energy (BOE) has estimated the gross value of industrial output will achieve 500 billion TWD in 2030.

Table 2. Roadmap of the thousand wind turbines project in Taiwan

\begin{tabular}{|c|c|c|c|c|c|}
\hline Year & 2014 & 2015 & 2020 & 2025 & 2030 \\
\hline $\begin{array}{l}\text { Onshore } \\
\text { (No. of turbines) }\end{array}$ & $\begin{array}{l}\text { 632.6MW } \\
(319)\end{array}$ & $\begin{array}{l}866 \mathrm{MW} \\
(350)\end{array}$ & $\begin{array}{l}1,200 \mathrm{MW} \\
(450)\end{array}$ & $\begin{array}{l}1,200 \mathrm{MW} \\
(450)\end{array}$ & $\begin{array}{l}1,200 \mathrm{MW} \\
(450)\end{array}$ \\
\hline $\begin{array}{l}\text { Offshore } \\
\text { (No. of turbines) }\end{array}$ & 0 & $\begin{array}{l}15 \mathrm{MW} \\
(4)\end{array}$ & $\begin{array}{l}\text { 600MW } \\
(120)\end{array}$ & $\begin{array}{l}1,800 \mathrm{MW} \\
(360)\end{array}$ & $\begin{array}{l}3,000 \mathrm{MW} \\
(600)\end{array}$ \\
\hline Total & $\begin{array}{l}\text { 632.6 MW } \\
(319)\end{array}$ & $\begin{array}{l}\text { 881 MW } \\
(354)\end{array}$ & $\begin{array}{l}1,800 \mathrm{MW} \\
(570)\end{array}$ & $\begin{array}{l}3,000 \mathrm{MW} \\
(810)\end{array}$ & $\begin{array}{l}4,200 \mathrm{MW} \\
(1,050)\end{array}$ \\
\hline
\end{tabular}

At the beginning, the offshore will combine the technologies from advanced countries and the ones from Taiwan. The government of Taiwan will continuously support industries in Taiwan to build the key technology of offshore wind energy.

In the national energy project of Taiwan, there are three related authorities involve in the development of the offshore wind energy, which are the Bureau of Energy (BOE), the Industrial Development Bureau (IDB), and the Bureau of Standards, Metrology and Inspection (BSMI). Among the three government institutions, the BSMI is in charge of the standard implementation and the certification. Thus, the BSMI plans to construct a wind turbine test site. The test site would be located at Taichung harbor to match the offshore wind industry development requirements. The goal of the test site is to provide offshore wind turbine type testing and certification service, which include the wind turbine and its key components, power quality, and the communication for monitoring and control of the wind turbine.

Even though there are lots of benefits for development of offshore, we still have to conquer many grave challenges in Taiwan. For example, we locate the subtropical zone, so there are much tougher conditions for building key technology of the offshore wind power. The turbines must bear the wind with more salt than Europe or America and the earthquake usually happened in Taiwan.

Because it is in the initial phase of developing smart grid in Taiwan, we have to solve the problems of interoperability of communication which might happen in the future. It is a significant issue we must figure out and research the standard in interoperability. Thus, each part of smart grid could communicate with each other, and the main backbone of power system can manage the power easily.

\section{Communication of Wind Turbines}

\subsection{Communication standard for wind power plant}

IEC 61400-25 is a communication standard for control and monitoring in wind power plant [8], [9]. The standard is based on IEC 61850, which is originally a communication standard for substation automation. Recently, it is extended as a communication standard for power utility automation.

The IEC 61400-25 standards define the information models in the wind power plant (IEC 61400-25-2) [10], which is used to describe the real world component of the wind power plant, so that there is a common method for the external clients and users to describe many sub-components in the wind power plant. The information exchange model is also defined in the series of standards (IEC 61400-25-3) [11]. The functions and data of each information model (component) are illustrated in detail. Finally, the models are mapping to the existing communication profiles, so that the wind turbines can be controlled and monitored by the users [12]. 


\subsection{Information model}

As shown in Fig. 1(a), the real world wind power plant physical devices are modeled as logical devices in the virtual world. The information of each component (logical node class) of the wind power plant logical devices, such as WTUR-wind turbine general information, WROT-wind turbine rotor information, WGEN-wind turbine generator information, is defined in this standard. There are also some logical node classes, for example, XCBR-circuit breaker, MMXU- measuring for operative purpose, have been defined in the IEC 61850 series standards.

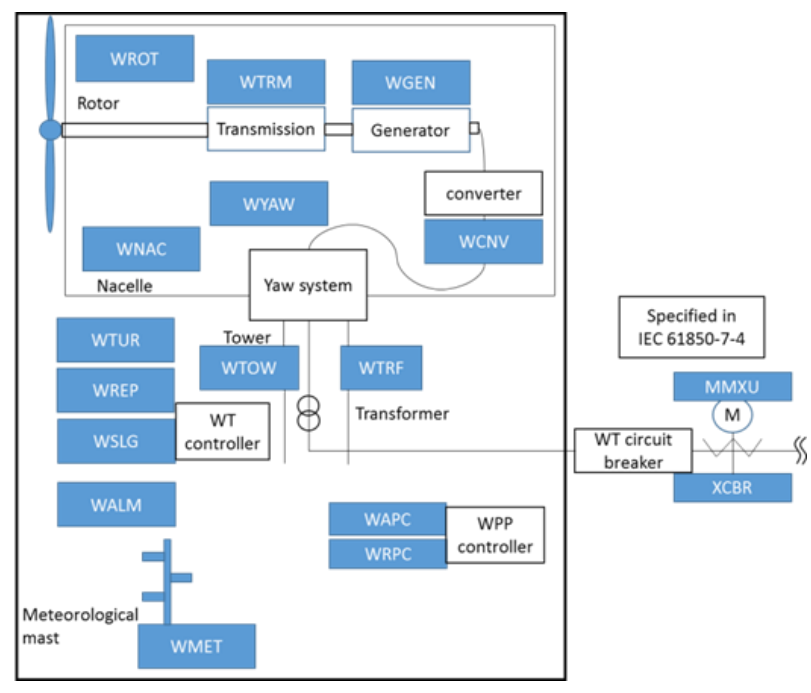

(a)

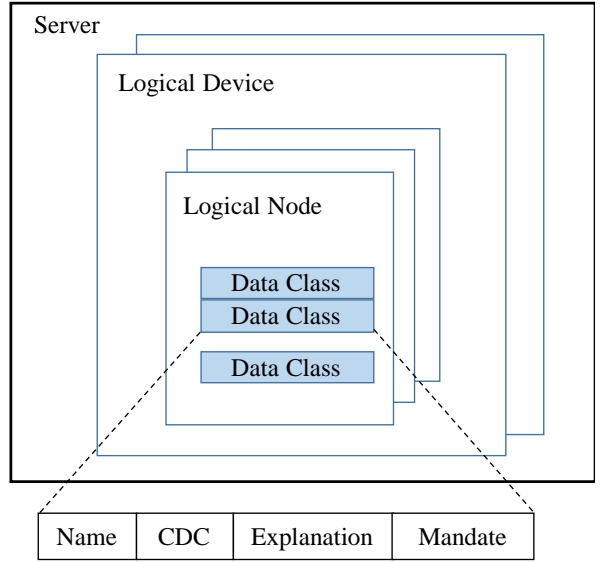

(b)

Fig. 1. Information model: (a) the example of the logical device model of physical device (b) structure of the information model.

The structure of the information model of wind power plant, which is defined in the IEC 61400-25-2 [10], is a top-down view model as shown in Fig. 1(b). There are four layers of the model. Table 3 shows that each layer has its property and presents all of the information in the wind power plant.

Table 3. Structure of the wind power plant information model

\begin{tabular}{lll}
\hline \hline & Layer & Description \\
\hline \hline 1 & Server & $\begin{array}{l}\text { The top layer of the model of the wind power plant, which could present the information of } \\
\text { the whole wind power plant. }\end{array}$ \\
\hline 2 & $\begin{array}{l}\text { Logical Device } \\
\text { (LD) }\end{array}$ & $\begin{array}{l}\text { The second layer of the model. Each wind turbine could be a logical device, so there may be } \\
\text { many logical devices under the server. }\end{array}$ \\
\hline 3 & $\begin{array}{l}\text { Logical Node } \\
\text { (LN) }\end{array}$ & $\begin{array}{l}\text { The third layer of the model, which present the sub-component of the wind turbine. For } \\
\text { example, the rotor and the wind turbine tower. }\end{array}$ \\
\hline 4 & Data Class & $\begin{array}{l}\text { The bottom layer of the model. The Data Class contains the parameters of the sub-component } \\
\text { of the wind turbine, which are often obtained by the sensors. The structure of the Data Class } \\
\text { is defined by the Common Data Class (CDC). }\end{array}$ \\
\hline \hline
\end{tabular}

Table 4. Four categories of the wind power plant information model

\begin{tabular}{lll}
\hline \hline & Category & Description \\
\hline \hline 1 & Wind Turbine & $\begin{array}{l}\text { The components are including Rotor, Transmission, Generator, } \\
\text { Converter, Nacelle, Yaw system, Tower, Alarm system. }\end{array}$ \\
\hline 2 & Meteorological System & Meteorological conditions of the wind power plant. \\
\hline 3 & Wind Power Plant Management System & Wind power plant control. \\
\hline 4 & Electrical System & Wind power plant grid connection. \\
\hline \hline
\end{tabular}


According to the IEC 61400-25, the coverage area of the information model of the wind power plant can be classified into four categories. The category and the corresponding components are shown in Table 4.

For example, a wind power plant consists of several components. The information of wind power plant breaks down into several logical nodes as shown in Table 5.

The IEC 61400-25 and the IEC 61850 series standards describe the wind power plant well, and let the external clients and users have the common language to access these logical devices and logical nodes.

Table 5. Wind power plant general logical nodes

\begin{tabular}{ll}
\hline \hline LN classes & Description \\
\hline \hline WTUR & Wind turbine general information \\
\hline WPPD & Wind power plant general information \\
\hline WALM & Alarm information \\
\hline WMET & Meteorological information \\
\hline WAPC & Active power control information \\
\hline WRPC & Reactive power control information \\
\hline WSLG & State log information \\
\hline WALG & Analogue log information \\
\hline WREP & Report information \\
\hline WAVL & Availability information \\
\hline LTIM & Time management \\
\hline \hline
\end{tabular}

\subsection{Information exchange model}

In order to access the structure and content of the information models, the information exchange model is provided in IEC 61400-25-3 [11].

As shown in Fig. 2, the services and interfaces are defined for the external clients to interact with the logical devices and logical nodes in the wind power plant. The logical nodes contain many data, which can be grouped into data sets.

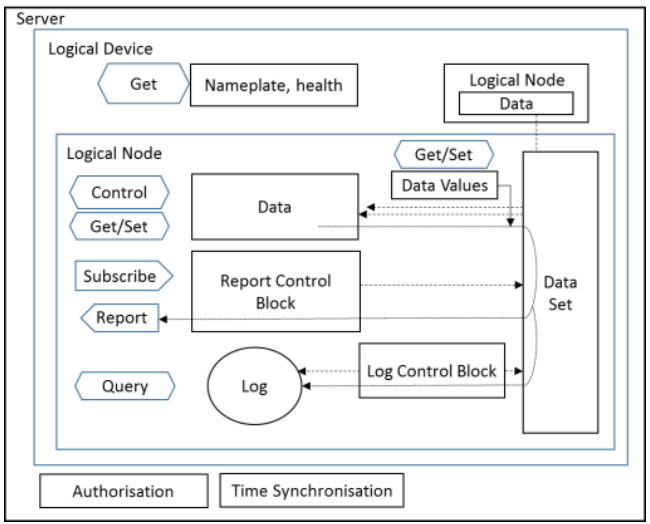

Fig. 2. Information exchange model of wind power plant.

The information exchange model can be classified into two groups: operational function and management function.

As shown in Table 6, the operational function including Authorization, Control, Monitoring, Reporting and Logging. The management function includes Diagnostics, User and access management, Setup, and Time synchronization.

The Authorization model of the operational function is used to let the client and server exchange the data safely. By checking the identification information provided by the client, it can provide the service 
for client to access the server. The Control model of the operational function defines the control function to allow the client controlling the device in a specific period of time. The Monitoring, Reporting and Logging model of the operational function defines the three methods to access the information independently.

Table 6. Information exchange model

\begin{tabular}{l|l|l}
\hline \hline $\begin{array}{l}\text { Functional } \\
\text { group }\end{array}$ & Information exchange model & Description \\
\hline \hline \multirow{4}{*}{ Operational } & Authorization & $\begin{array}{l}\text { Authentication and restriction of access to operational and management } \\
\text { functions }\end{array}$ \\
\cline { 2 - 3 } & Control & Control of operational devices \\
\cline { 2 - 3 } & Monitoring & Monitoring of current data and change of data of operational devices \\
\cline { 2 - 3 } & Reporting and logging & Trigger controlled continuous scanning and recording of values and events \\
\hline \multirow{3}{*}{ Management } & Diagnostics & Self-monitoring of devices \\
\cline { 2 - 3 } & User and access management & Setting up users, access rights and monitoring access \\
\cline { 2 - 3 } & Setup & Device configuration management \\
\cline { 2 - 3 } & Time synchronization & Synchronization of device clocks \\
\hline \hline
\end{tabular}

The first method is shown in Fig. 3(a). According to the demand of the client, it sends the request message to the server. After the server receives the request, the server sends back the data immediately. The commonly command is Get and Read.

The second method is shown in Fig. 3(b). The historic values would be logged at the device (server). The client could query the log in a range of time or the specific data after a timestamp.

The third method is shown in Fig. 3(c). After the client configures the subscription information to the server, the client waits for the response from the server. The server would send the message depending on the trigger condition, which is often periodically. The server sends the values to the subscriber (client) until the subscription being disabled.

The data set is important for the Report and Log functions. For example, some devices could record the data periodically. If the external clients want to retrieve some of the logged data, it can send the request to the correspondent device. Then, the rules of logging are defined in the Log Control Block (LCB). The logged data can be collected into data sets and retrieved by user. Similarly, the rules of reporting are defined in the Report Control Block (RCB).

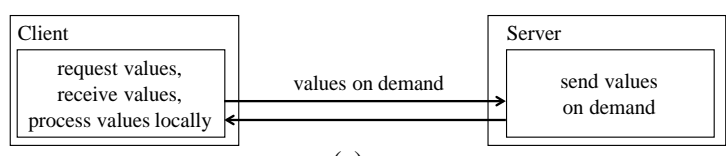

(a)

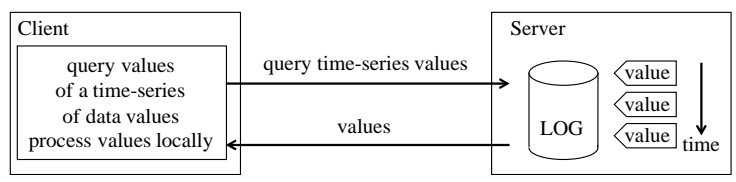

(b)

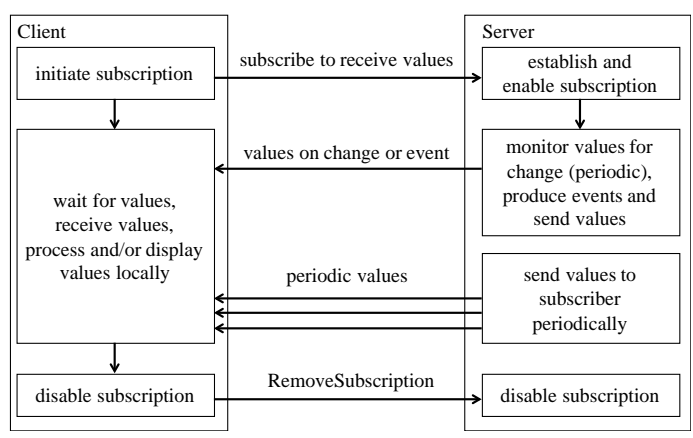

(c)

Fig. 3. The operational function to access the information: (a) retrieve on demand (b) query the $\log$ data (c) publisher/subscriber reporting.

\subsection{Mapping to the communication profile}

The information model and information exchange model are defined in IEC 61400-25-2 and IEC 61400-25-3. In order to exchange the data over the network, the models are mapping to the specific communication profile. There are 5 communication profiles defined in the IEC 61400-25-4 [12], which 
are web services, OPC XML-DA, IEC 61850-8-1 MMS, IEC 60870-5-104, and DNP3. Fig. 4 shows the conceptual architecture of the mapping to communication profiles.

Different communication profiles have their own characteristics. For example, DNP3 and IEC 608705-104 are the TCP/IP based communication protocol. However, IEC 61850 even provides metadata in the devices, real-time applications (GOOSE, SMV), and system configuration language.

The user can choose the suitable communication profile according their system. There is also a reason to decouple the information model and information exchange model from the communication profile. After the models are well defined, the models can be used for a long time. However, the communication technique may improve with the time. Once there is a better communication technique invented, the models can be mapped to the new communication profile.

In Taiwan, the main backbone of power system uses the DNP3 as the communication protocol, and the RTU (Remote Terminal Unit) of Taiwan power system also provide the DNP3 communication port. In order to let the offshore wind turbine interoperates well with the original power system, the communication profile of offshore wind turbines should be able to integrate with the RTU.

The concept of communication of wind energy in Taiwan is shown in Fig. 5. The wind turbine connects to the power system of the Taiwan Power Company (TPC). In order to control and dispatch the power, TPC needs to monitor the information in the switchyard, which includes the state of circuit breaker (CB), power, analog input (AI), digital input (DI) and so on. These data will be collected by the RTU, and then send to the substation and the Dispatch and Control Center (DCC). The communication protocol used by TPC is DNP3. In order to interoperate well between the master and the slave side (for example, the RTU in the substation and the RTU in the switchyard of wind power plant), it is essential to define the communication profile well.

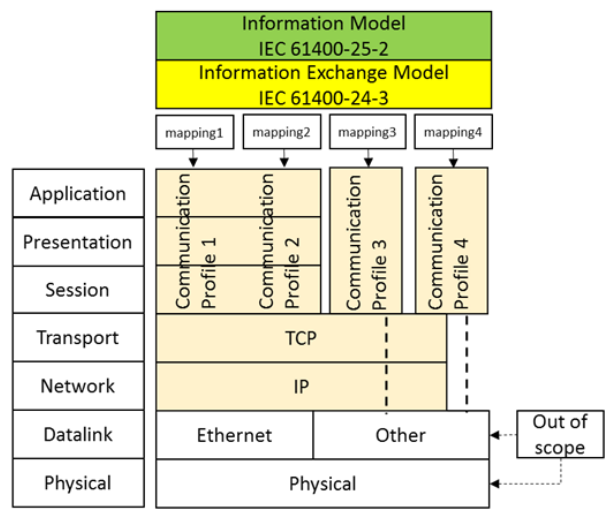

Fig. 4. Concept of mapping the information model and information exchange model to the communication profile.

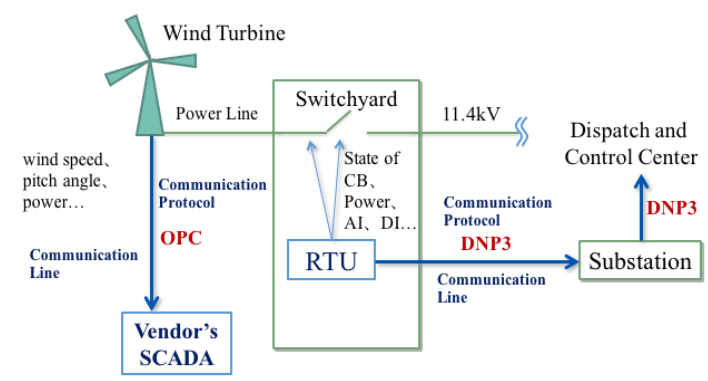

Fig. 5. Concept of communication of wind energy in Taiwan.

However, the information of the wind turbine (such as wind speed, pitch angle of the rotor, power... and so on) is not necessary for the DCC. The information is essential for the operator of the wind power plant (such as Infravest and the Department of Renewable of TPC) and the manufacture of the 
wind turbine. For example, the Department of Renewable Energy (DoRE) of TPC uses the OPC communication protocol to collect the information of the wind turbines. But the different wind power plants may use different SCADA systems, the DoRE of TPC have to integrate different systems to get the information.

Using the IEC 61850 in communication networks and systems has been a trend for power utility automation. The IEC 61400-25 is also promoted by the USE61400-25 user group within the wind power industry. For the good of integration of wind power with the power system, IEC 61400-25 might be a standard solution for all parties - system integrators, vendors as well as the customer.

\section{Conclusion}

In this paper, the development of wind energy in Taiwan is illustrated, which includes the background of onshore wind energy and the demonstration project of the offshore wind energy.

Recently, Taiwan official BSMI will set up a test site in Taichung. The offshore wind turbine should meet the highest standard of IEC Type Certification class 1A. The turbine under test will connect to the power system. The communication for control and monitoring would be important. The integration of communication protocols will be considered in the phase of testing to ensure the success of interoperability in the offshore wind plant.

\section{Acknowledgements}

This paper is based on the project "Study of Standard and Certification Program for Communication of Offshore wind turbine" which is supported by Bureau of Standards, Metrology and Inspection, Ministry of Economic Affairs (BSMI, MOEA), R.O.C.

\section{References}

[1] Quecedo EST, Canales I, Villate JL, Robles E, Apñanz S. The use of IEC 61400-25 standard to integrate wind power plants into the control of power system stability. Presented at: European Wind Energy Conference and Exhibition, 2007.

[2] Ahmed MA, Kim YC. Hierarchical communication network architectures for offshore wind power farms. Energies, 2014; 7(5):3420-3437.

[3] Ahmed MA, Kim YC. Communication network architectures for smart-wind power farms. Energies, 2014; 7(6):3900-3921.

[4] Johnsson A, Højholt LE. Use of IEC 61400-25 to secure access to key O\&M data. Presented at: European Offshore Wind Conference, 2007.

[5] Lee JH, Seo MJ, Kim GS, Lee HH. IEC 61400-25 interface using MMS and web service for remote supervisory control at wind power plants. In: Proc. of International Conference on Control, Automation and Systems, 2008:2719-2723.

[6] Seo MJ, Kim TO, Lee HH. Implementation of web services based on IEC 61400-25 for wind power plants. In: Proc. of ICCAS-SICE, 2009:2082-2086.

[7] Global Energy Research Council. (April 2014). Global wind report-annual market update 2013. [Online]. Available: http://www.gwec.net/wp-content/uploads/2014/04/GWEC-Global-Wind-Report_9-April-2014.pdf

[8] Wind Turbines - Part 25-1: Communications for Monitoring and Control of Wind Power Plants - Overall Description of Principles and Models, IEC Standard 61400-25-1 (2006).

[9] Chou YC. Study on the supervisory control system and web service of wind turbine implementing the IEC 61400-25. MS thesis. Department of Engineering Science and Ocean Engineering, National Taiwan University. Taipei, Taiwan; 2014.

[10] Wind Turbines - Part 25-2: Communications for Monitoring and Control of Wind Power Plants - Information Models, IEC Standard 61400-25-2 (2015).

[11] Wind Turbines - Part 25-3: Communications for Monitoring and Control of Wind Power Plants - Information Exchange Models, IEC Standard 61400-25-3 (2015).

[12] Wind Turbines - Part 25-4: Communications for Monitoring and Control of Wind Power Plants - Mapping to Communication Profile, IEC Standard 61400-25-4 (2008). 